\title{
Marketing: definições, aplicações, tendências e desafios do profissional
}

Guilherme Minuzzi

Especialista em Estratégias de Marketing pela Universidade de Caxias do Sul (UCS).

E-mail: <gminuzzi@outlook.com> Endereço: Rua Isidoro Cavedon, 886 - São Roque /

Bento Gonçalves - RS - 95700-000

Fabiano Larentis

Doutor em Administração UFRGS, Docente do Programa de Pós-graduação em Administração (PPGA UCS), Universidade de Caxias do Sul.

E-mail: <flarenti@ucs.br>

Endereço: Tray Montenegro, 20/401

CEP 95700-000 Bento Gonçalves - RS

\section{Resumo}

O presente estudo busca analisar como o conceito de marketing é tratado nas práticas organizacionais, bem como a importância da área para as corporações, os principais desafios enfrentados pelo profissional de marketing e as tendências da área. Desenvolveu-se esta pesquisa exploratória, com profissionais de áreas relacionadas a marketing e também de áreas não-relacionadas, buscando analisar sua percepção sobre a disciplina, inserida no contexto organizacional. Observou-se uma visão limitada sobre sua atuação, falta de consenso sobre seu conceito e um nível considerável de interesse das outras áreas, representado sobre sua opinião acerca da importância da área para as organizações. Diante disso, estimula-se a discussão sobre uma possível revisão do papel do marketing nas empresas, bem como das funções exercidas pelo profissional da área.

Palavras-chave: Conceito de Marketing. Profissional de Marketing. Tarefas de Marketing. Tendências de Marketing. 


\section{Introdução}

Marketing é praticado e ensinado desde a antiguidade, tornando-se uma disciplina acadêmica no século XX (Bartels, 1988; Shaw $\&$ Jones, 2005). No entanto, talvez o marketing seja uma das áreas mais mal compreendidas dentro de uma organização. Por ser uma área extremamente abrangente, seu significado gera muitas dúvidas. Para uns, trata-se de técnicas de venda. Para outros, trata-se de publicidade e propaganda. Antes de tratar especificamente do seu conceito, é importante compreender a evolução dos seus estudos ao longo do tempo.

$\mathrm{O}$ entendimento de marketing passou por muitas mudanças desde que começou a ser estudado, logo após a Revolução Industrial e o surgimento da produção em massa. $\mathrm{Na}$ era da Revolução Industrial, a preocupação do marketing era a produção de mercadorias com a melhor qualidade possível, pois como explana Las Casas (2001, p. 21), "os consumidores estavam ávidos por produtos. A produção era quase artesanal. Com a Revolução Industrial apareceram as primeiras indústrias organizadas aplicando a administração científica de Taylor. A produtividade aumentou. Assim mesmo a ideia dos empresários e a disponibilidade de recursos eram fatores determinantes na comercialização".

A produção em série idealizada por Henry Ford começou a trazer à tona um problema: excesso de oferta. Com isso o marketing passou a enfatizar a venda, conforme aborda Cobra (1992, p. 32): "Após concentrar esforço na otimização da produção e na distribuição, a partir de 1930, o processo de vendas começou a ser observado como uma das fraquezas das atividades mercantis, e desde então a área de vendas passou a receber grande atenção".

Porém, com o passar dos anos, mais precisamente a partir da década de 1950, as empresas começaram a perceber que manter o foco nas vendas a qualquer custo não seria o melhor caminho. Estratégias agressivas de promoção e vendas oneram muito o custo do produto final e reduzem as margens de lucro. Sem falar que esse tipo de estratégia não conquista a fidelidade do consumidor, que muitas vezes não voltava a consumir os produtos do mesmo fabricante. Conforme indica Webster Jr. (1994), na antiga perspectiva de marketing, objetivava-se fazer a venda; sob a nova perspectiva, procura-se desenvolver um relacionamento com os clientes onde a venda é só o começo.

Desde então se passou a buscar um entendimento maior do mercado, na forma como define Ritchie (2012, p. 25): "É identificar oportunidades de mercado para os produtos e serviços que os clientes desejam ou de que necessitam, e coordenar os recursos internos e externos de modo a entregar produtos e prestar serviços com uma margem de lucro saudável. É também comunicar-se com possíveis clientes-alvo de modo a posicionar as ofertas de sua empresa no consciente deles".

É possível notar que no estudo contemporâneo de marketing, todos os conceitos passados estão compostos num ciclo, onde primeiro pensa-se no mercado para depois produzir. Ou seja, primeiro se entende o mercado para depois atendê-lo, como ensina Richers (2000), na sua definição de que marketing tem relação com entender e atender mercados, ou seja, uma área organizacional de relacionamento com os mercados. Em relação a isso, convém ressaltar que neste trabalho considera-se que as empresas possuem, além de marketing, outras três grandes áreas de ação no sentido amplo - produção/operações, administrativo/financeiro e gestão de pessoas.

Na prática, todavia, o conceito de marketing em seu sentido mais amplo, não é entendido pela maioria das pessoas, que comumente o associa a vendas ou publicidade/ propaganda, ou seja, dentro do composto de marketing (Campomar e Ikeda, 2006). O pro- 
fissional de marketing, muitas vezes, limita-se a atuar em comunicação, envolvendo-se muito pouco nas demais partes do composto de marketing (produto, preço e distribuição). Face a esta discrepância, surgem algumas questões a serem refletidas: Qual o significado de marketing e o papel do profissional de marketing nas empresas? Qual a importância que o marketing tem, em comparação a outros setores da empresa?

Com o objetivo de analisar o papel e a importância do marketing nas organizações, este artigo foi estruturado da seguinte forma. Além desta introdução, primeiramente se apresenta o referencial teórico. Em seguida, se desenvolvem o método e a análise dos resultados, bem como se apresentam as considerações finais.

\section{Referencial Teórico}

O referencial teórico teve como foco três principais temas: conceitos de marketing, tarefas de marketing e percepção do marketing.

\subsection{Conceitos de marketing}

O marketing é uma disciplina acadêmica nova. Segundo Bartels (1988) e Oliveira (2007), pode-se delimitar seu surgimento no início do século XX nas escolas de negócios dos Estados Unidos. Este período coincide com um elevado crescimento populacional e de renda. Com o aumento do número de consumidores, as empresas perceberam que sua relação com este público tornava-se mais complexa, então surgiu a necessidade de entender melhor o funcionamento das relações comerciais com estes clientes.

O marketing sempre teve uma relação muito estreita com a dinâmica social. Seus conceitos mudam conforme a sociedade muda suas formas de conviver, consumir e de pensar, desenvolvendo-se de um estágio de economia artesanal para um sistema que compreende a divisão do trabalho e industrialização (Révillion, 2001). Todavia, o aumento da produção em larga escala trouxe à tona um grande problema: para quem vender? Esta posição de transferir o foco do produto ao cliente é sustentada por Levitt (1985), em seu famoso artigo "A Miopia em Marketing”, ao abordar o ciclo auto-ilusório de grande ascensão de um negócio e queda despercebida, gerado pela crença de que tal desenvolvimento é assegurado por uma população em crescimento e mais rica; de que não há substituto para o principal produto da indústria; pela fé demasiada na produção em massa e nas vantagens na queda rápida dos custos unitários; pela preocupação com um produto que se presta à experimentação científica cuidadosamente controlada, ao aperfeiçoamento e à redução dos custos de fabricação.

Nesse ínterim, em razão da Revolução Industrial e suas melhorias fabris, a produção das empresas cresceu de forma exponencial, talvez mais até que o mercado consumidor, e o grande desafio a partir deste momento era o de começar a estudar o mercado em busca de novas oportunidades de negócios e em busca de formas mais eficientes de distribuição, ou seja, formas mais eficientes de como fazer o produto chegar até o consumidor. Foi o princípio dos estudos do que podemos chamar de marketing contemporâneo.

A partir disso, chega-se à última definição elaborada pela American Marketing Association - AMA (2013) em 2007, que apresenta marketing como sendo "a atividade, conjunto de instituições e processos para criar, comunicar, entregar e trocar ofertas que tenham valor para os clientes, parceiros e sociedade em geral." Tal definição é uma evolução em relação à primeira, de 1935, que tratava marketing como "a realização de atividades de negócio dirigidas ao fluxo de bens e serviços 
dos produtores aos consumidores", ou seja, com um enfoque mais na distribuição.

Também evoluiu em relação à de 1985, na qual ficava evidente a preocupação com a gestão do composto de marketing e à satisfação das necessidades dos clientes e dos objetivos organizacionais: "processo de planejamento e execução da concepção/conceito, da definiçãa do preço, da promoção e da distribuição de bens, idéias e serviços para criar trocas que satisfaçam objetivos individuais e organizacionais". Ambas, todavia, têm presente o elemento troca, pilar central do marketing (Kotler \& Keller, 2006).

Na definição de 2004, Marketing era tratado como "função organizacional e um conjunto de processos que envolvem a criação, a comunicação e a entrega de valor para os clientes, bem como a administração do relacionamento com eles, de modo que beneficie a organização e seus públicos interessados (stakeholders)". Em relação à de 2007, a diferença está basicamente da entrega de valor para a entrega de ofertas que tenham valor. Tal como indicado pela AMA (2013), a definição de 2007 amplia seu escopo em relação às demais, deixando de ser tão somente um processo de gestão.

Desta forma, sendo uma disciplina constantemente em mutação, o marketing, que evoluiu do foco na gestão de produtos nas décadas de 1950 e 1960 para o foco na gestão de clientes, marcas e relacionamentos nas últimas décadas, dá mais um passo, em direção ao chamado Marketing 3.0, ou a era voltada para valores. O Marketing 3.0 é conceituado por Kotler, Kartajaya, e Setiawan (2010, p. 4) da seguinte forma: "Em vez de tratar as pessoas simplesmente como consumidoras, os profissionais de marketing as tratam como seres humanos plenos: com mente, coração e espírito. Cada vez mais os consumidores estão em busca de soluções para satisfazer seu anseio de transformar o mundo globalizado num mundo melhor. [...] Buscam não apenas satisfação funcional e emocional, mas também satisfação espiritual, nos produtos e serviços que escolhem." Ou seja, são valorizadas a experiência do consumidor como ser humano pleno, os seus relacionamentos e as questões atinentes à sustentabilidade (Achrol \& Kotler, 2012).

Em relação a isso, apesar de nenhuma empresa ter uma estrutura completamente focada no cliente, há diversas efetuando essa transição. A mudança mais dramática será quando o departamento de marketing se tornará um departamento do cliente, substituindo o CMO (Chief Marketing Officer) pelo CCO (Chief Customer Officer), com gerentes de marca e de produto respondendo a gerentes de clientes. Tais mudanças serão avaliadas não somente pela rentabilidade do produto, mas pela rentabilidade do cliente (Rust, Moorman, \& Bhalla, 2010).

Portanto, em um cenário globalizado, em épocas de crises econômicas, escalada de violência, epidemias e desastres naturais, as pessoas buscam, na medida do possível, tornar o mundo um lugar melhor para viver. $\mathrm{E}$ valorizam os produtos e serviços de empresas que também têm esta mesma preocupação, que são engajadas em causas sociais e preservam o meio-ambiente. Consumir produtos politicamente corretos, apoiar a comunidade em causas sociais e compartilhar informações úteis à sociedade por meio das redes sociais, são as formas que estes consumidores modernos encontram para tornar o mundo um lugar melhor.

Por fim, apesar de haver diversas definições sobre marketing e embora a visão de marketing tenha mudado muito ao longo do tempo, pode-se afirmar que seu cerne está em entender o mercado e atendê-lo, o que pode continuar servindo de guia, através das várias outras mudanças nos movimentos sociais, econômicos, políticos, legais e ambientais que hão de vir e que irão influenciar as formas de praticar e enxergar o marketing. 


\subsection{Tarefas de marketing}

As funções do marketing talvez estejam entre as mais mal compreendidas dentro de uma organização, pois são percebidas de diversas formas, por diferentes pessoas, conforme exemplifica Ritchie (2012, p. 25): "Alguns pensam tratar-se das atividades promocionais que auxiliam a função de vendas a gerar receita e convencer os clientes a adquirir produtos e serviços. [...] Outros enfatizam os aspectos do marketing de produtos e do desenvolvimento de produtos quando se trata de definir e fixar os preços em mercados competitivos. [...] Existem ainda aqueles que equiparam o marketing à chamada propaganda "acima da linha" [...]." O marketing envolve sim todas estas funções, mas ele é muito mais que isso. É tarefa do marketing, também, identificar oportunidades de mercado para a empresa, coordenar os recursos internos e externos para fazer o produto/serviço chegar da melhor forma possível ao cliente final, e também é sua tarefa coordenar a comunicação junto aos clientes-alvo de modo a posicionar a oferta tanto em relação a aspectos cognitivos quanto associados às emoções.

Ou seja, líderes de marketing devem decidir acerca de quanto investir em propaganda, quando fazer campanhas de vendas ou de reforço de marca, que mudanças agregar nos produtos ou serviços da empresa e também decidir sobre o tamanho e localização da força de vendas. Todas estas decisões devem ser tomadas com base em dados colhidos no mercado. Estes dados incluem, entre outros, a evolução das vendas no período, aspectos legais, ambientais, políticos, econômicos, sociais e culturais. O profissional de marketing precisa também estar atento aos movimentos das empresas concorrentes a fim de manter a posição de mercado da empresa ou de ampliá-la (Kotler, 2000; Ritchie, 2012; Troiano, 2009).
Kotler (2000) afirma que os profissionais de marketing são responsáveis por gerenciar a demanda, ou seja, procuram influenciar o nível, a velocidade e a composição da demanda. Além disso, Kotler e Keller (2006) resumem em oito as principais tarefas do marketing: desenvolvimento de estratégias e planos de marketing, conexão com clientes, construção de marcas fortes, desenvolvimento das ofertas ao mercado, entrega e comunicação de valor, captura de oportunidades de marketing e do desempenho, e, por fim, a obtenção de um crescimento de longo prazo bem-sucedido.

Voltando à afirmação de Kotler, de que o profissional de marketing é responsável pela gestão da demanda, é possível elencar oito tipos de demanda, também segundo o mesmo autor (2000): demanda negativa, demanda inexistente, demanda latente, demanda em declínio, demanda irregular, demanda plena, demanda excessiva e demanda indesejada. Gerenciar a demanda significa identificar o nível de demanda que o mercado da empresa se encontra, e a partir disso tomar as decisões que servirão para a empresa alcançar os objetivos traçados.

Para Baker (2005), a função de marketing, basicamente, é responsável por gerenciar o composto de marketing (produto, preço, distribuição e comunicação). O papel do marketing é traçar as estratégias para cada um dos elementos do composto, de acordo com os objetivos da organização e o posicionamento pretendido. Ou seja, é definir os rumos da organização trazendo insights do mercado para pautar a administração do portfólio de produtos; analisar os preços da concorrência a fim de traçar a melhor estratégia de preço, sempre levando em conta o posicionamento pretendido; escolher os canais de venda certos; e comunicar este posicionamento ao mercado.

O ponto chave para o marketing gerir seu composto depende, antes de mais nada, em 
segmentar o mercado, selecionar seu público-alvo e posicionar a oferta. Richers (2000) defende que as funções de marketing dependem de dois propósitos primordiais. Um está ligado a identificar segmentos de mercado ou oportunidades de demanda, inadequadamente satisfeitas pelas ofertas existentes no mercado, incluindo as da empresa; outro consiste em atender esses segmentos com o mínimo de recursos e custos operacionais. Sobre posicionamento, Kotler (2000, p. 321), o define como "o ato de desenvolver a oferta e a imagem da empresa para ocupar um lugar destacado na mente dos clientes-alvo".

Assim, de acordo com Kotler e Keller (2006), estudar de maneira profunda os mercados de atuação aumenta a probabilidade de retenção de clientes e de lidar de forma proativa com a concorrência. No entanto, além de todas estas tarefas atribuídas ao marketing, os profissionais da área estão sendo cada vez mais cobrados para comprovar o retorno dos investimentos em marketing. Há uma máxima que afirma que "metade dos investimentos em marketing é jogada no lixo. Só não se sabe qual." Rosenwald (2005) acrescenta que não são suficientes o brilhantismo de uma iniciativa promocional ou a quantidade de prêmios outorgados, mas os resultados proporcionados em termos de lucro.

Fica evidente, portanto, que em linhas gerais é tarefa do marketing definir mercados-alvo e posicionamentos, bem como administrar o composto de marketing através dos 4A's, apresentados por Richers (2000): análise, adaptação, ativação e avaliação. $\mathrm{Ou}$ seja, vai além de atividades associadas tão somente à promoção das ofertas. Todavia, em muitas organizações, o profissional de marketing é visto como responsável apenas pela comunicação da empresa com o mercado, participando muito pouco das decisões que envolvem, por exemplo, o lançamento de um produto, estratégias de precificação ou decisões acerca da melhor maneira de distribui- ção (Camponar \& Ikeda, 2006; Silveira, Esteves, \& Rossi, 2013).

Conclui-se que o escopo do marketing é muito amplo e atua sobre todo o composto de marketing, e não apenas na comunicação ou vendas, por exemplo. Fenômenos emergentes, como os associados à experiência do consumidor, às redes sociais, tanto de indivíduos quanto de empresas, e à sustentabilidade (Achrol \& Kotler, 2012), reforçam isso. E sendo responsável por lidar com tais fenômenos, sua tarefa principal é entender o mercado para posicionar a oferta, entregando e comunicando valor, conforme defende Ritchie (2012).

\subsection{Percepção do marketing}

Marketing é geralmente visto como um departamento, ou função, de apoio ao setor de vendas, ao qual presta este apoio através de campanhas publicitárias, materiais de venda e participação em feiras e eventos, sendo percebido como vendas; propaganda para aumentar as vendas; ações para promover pessoas; atividades para criar necessidade; forma capitalista de fazer as pessoas quererem o que não precisam (Campomar \& Ikeda, 2006).

Com base nisso, o marketing atua exclusivamente no composto da promoção, ao invés de gerenciar o mix como um todo. $\mathrm{E}$ esta concepção é geralmente adotada pelas empresas, em suas estruturas organizacionais. Richers (2000) reforça esta percepção errônea sobre o marketing. Segundo ele, para a grande maioria dos brasileiros, o marketing não é encarado como forma para aumentar a eficácia da empresa como um todo, mas mais como uma atividade de suporte.

Frente a esta afirmação, podem-se destacar dois grandes desafios ao profissional de marketing a fim de mudar esta percepção mal-entendida da disciplina: o primeiro deles 
é explicar aos stakeholders toda a dimensão do marketing. É, conforme apresenta $\mathrm{Ba}$ ker (2005), identificar e agir sobre as coisas e pessoas que necessitam mudar dentro da empresa para que a estratégia externa seja implementada de forma adequada. Ou seja, é mostrar como o marketing surgiu, a evolução dos seus conceitos, suas tarefas e no que ele impacta na organização.

E o segundo desafio é desenvolver métricas de desempenho confiáveis, que mostrem o resultado dos investimentos na área. Ritchie (2012) reforça que a gestão do desempenho de marketing se tornou um aspecto crítico da disciplina nos últimos anos e deve continuar assim. Para ele, os valores reais e mensuráveis devem ser conhecidos e transmitidos para que a contribuição do marketing seja reconhecida.

\section{Metodologia}

\subsection{Delineamento}

A pesquisa foi realizada em duas etapas. Uma etapa qualitativa e exploratória, através de um estudo qualitativo básico ou genérico, relevante para se descobrir e entender um fenômeno, um processo ou as visões de mundo das pessoas envolvidas (Merrian, 2009). Esta etapa foi realizada com profissionais e especialistas da área de marketing, objetivando entender o porquê da má compreensão da disciplina e os principais conceitos de Marketing. Os entrevistados descreveram livremente suas definições e visões sobre a disciplina. Já a segunda etapa foi quantitativa e descritiva, através de uma survey. Esta etapa foi realizada junto a profissionais de diversas áreas, no intuito de analisar a percepção das demais áreas organizacionais sobre o marketing.

\subsection{Participantes do estudo e amostra}

A pesquisa qualitativa foi aplicada junto a um grupo de quatro respondentes, os quais têm formação acadêmica ou atuam na área de marketing. Dos quatro, uma respondente é Coordenadora de Marketing, dois são Professores e um é Publicitário. Já a pesquisa quantitativa foi realizada através de uma amostra por conveniência com 55 respondentes, de diferentes ocupações e formações, com o objetivo de analisar a percepção do marketing por outros setores organizacionais.

\subsection{Coleta e análise de dados}

A pesquisa qualitativa foi realizada através de entrevistas pessoais através de um roteiro semiestruturado com os profissionais indicados. O roteiro, composto por oito questões (Apêndice A), foi elaborado a partir do referencial teórico deste estudo, com questões associadas à definição, tarefas e desafios do Marketing, bem como funções do departamento de marketing e tendências da área. Tais entrevistas foram aplicadas durante o mês de Novembro de 2012, durando em torno de uma hora cada. Os resultados, gravados em áudio, foram transcritos para os formulários com as questões elaboradas. As entrevistas foram realizadas em locais fechados, individualmente, onde os entrevistados estivessem livres para dissertar acerca da disciplina. Com os dados da pesquisa qualitativa, foi realizada uma análise de conteúdo.

Por outro lado, a pesquisa quantitativa foi aplicada mediante um questionário online (ferramenta Google Docs - Apêndice B), respondida por profissionais de todas as áreas organizacionais. A seleção dos sujeitos ocorreu a partir de mensagens postadas em rede social (Facebook), nos perfis dos autores do estudo. Para os que apresentavam interesse em participar, era encaminhado aos seus 
e-mails o link para resposta. A integralidade dos que receberam os e-mails respondeu à pesquisa.

O questionário, predominantemente estruturado, composto por seis questões, sendo duas abertas, além das de caracterização da amostra, foi elaborado a partir dos resultados da etapa qualitativa. Continha questões a respeito do que os profissionais pensam sobre marketing, como eles enxergam sua importância na organização e sua opinião sobre que funções o marketing deve desempenhar nas empresas. A coleta ocorreu entre os meses de Outubro e Novembro de 2012, onde não havia a necessidade de os entrevistados se identificarem.

Os resultados da etapa quantitativa eram obtidos a partir de planilha eletrônica gerada pela ferramenta online de pesquisa. $\mathrm{Na}$ análise dos dados, através do software SPSS 18.0, foram efetuadas estatísticas descritiva (frequências e médias) e multivariada (ANOVA) (Malhotra, 2006). Em relação a isso, a amostra é composta de $58 \%$ de pessoas do sexo masculino, de $67 \%$ com ensino superior completo ou pós-graduação, 69\% com renda familiar superior a 5 salários mínimos, $39 \%$ com idade igual ou superior a 30 anos e $62,5 \%$ com atividades profissionais não relacionadas à área de marketing.

\section{Apresentação e análise dos resultados}

Para a apresentação dos resultados, omitiram-se os nomes dos respondentes, sendo identificadas, apenas, suas áreas de atuação e nível de escolaridade. As informações obtidas nas entrevistas foram organizadas da seguinte forma para análise: conceito de marketing, tarefas do marketing dentro da empresa, importância do Marketing para a corporação e tendências de marketing.

\subsection{Conceito de Marketing}

$\mathrm{Na}$ pesquisa qualitativa, realizada com profissionais da área, identificou-se que não houve consenso acerca do conceito de marketing, pois, conforme os relatos a seguir, é possível notar duas linhas de pensamento distintas. Uma delas aborda principalmente a ideia da satisfação dos clientes. E outra linha de pensamento opta por uma via mais gerencial, no sentido de análise de mercado, planejamento de estratégias e medição de resultados. Com base nas referência teóricas utilizadas no trabalho, entende-se que as duas linhas de pensamento citadas pelos entrevistados devem formar um conjunto, ou seja, é importante analisar o mercado, desenvolver estratégias e medir resultados, porém com o objetivo central de satisfazer os clientes.

É a disciplina que exercita, planeja e executa a construção das marcas a fim de proporcionar trocas satisfatórias para os consumidores e pessoas. (Professor)

Marketing é análise de mercado, ferramentas de planejamento, ações de relacionamento com clientes, tecnologias de desenvolvimento de produtos e serviços, modelos de distribuição e acesso, métodos de precificação adequados, uma boa comunicação integrada e ferramentas de controle das ações e dos resultados. Portanto, marketing é muito mais do que muitos pensam. (Coordenadora de Marketing)

Marketing é o processo de satisfazer clientes. (Professor)

É criar, trocar e gerar satisfação entre os interessados. (Publicitário)

Por outro lado, na pesquisa quantitativa, realizada com profissionais de diversas áreas, especificamente com a primeira questão do formulário, de natureza aberta e que solicitava uma definição de marketing, para $40 \%$ deles o marketing está relacionado estritamente com a função de promoção ou vendas, para $24 \%$ com a gestão de marketing (desde 
segmentação até o composto de marketing) e para $12 \%$ com atender necessidades, com a diferenciação de ofertas e com estratégia, respectivamente. Ou seja, $60 \%$ apresentou uma visão mais ampla a respeito de marketing, se aproximando das definições de marketing de Richers (2000) e da AMA (2007), levando em consideração as necessidades dos consumidores e outros elementos do composto de marketing, além da comunicação. Mesmo assim, é considerável a parcela dos que apresentam uma visão mais estreita.

\section{A American Marketing Association -} AMA (2013) define marketing como sendo "a atividade, conjunto de instituições e processos para criar, comunicar, entregar e trocar ofertas que tenham valor para os clientes, parceiros e sociedade em geral." Apresentou-se essa definição aos entrevistados na etapa qualitativa da pesquisa. $\mathrm{Na}$ opinião deles, este conceito é muito vago, e há muitas discrepâncias com a prática, evidência semelhante identificada no estudo de Silveira, Esteves e Rossi (2013), que analisou a opinião de pesquisadores de disciplinas acadêmicas associadas ao marketing.

Os comentários de alguns se aproximam mais da definição de Marketing da AMA de 1985, mais relacionada ao gerenciamento do composto de marketing, à satisfação das necessidades dos clientes e ao atingimento dos objetivos organizacionais.

Há uma diferença na prática, como a relação do marketing com os prestadores de serviço interno, que na prática acontece pouco. (Professor)

Acho que falta dizer que, apesar da teoria mencionada, o objetivo é gerar vendas, lucro, para que a empresa tenha resultado e força para tantos outros investimentos em marketing. (Coordenadora de Marketing)

Faltaria inserir questões relacionadas a meio-ambiente e sustentabilidade. No caso do Brasil, satisfazer o cliente ainda é a base do conceito de marketing. (Professor)
A única coisa que questionaria é a satisfação, que não aparece neste conceito. Ter valor para alguém não significa que lhe satisfaz. Tomo a liberdade de acrescentar isso na frase: "trocar ofertas que tenham valor e satisfaçam os clientes, parceiros e sociedade em geral". (Publicitário).

Em resumo, para os diversos setores corporativos, o marketing em boa parte dos casos é visto como um setor relacionado estritamente ao composto de promoção. Segundo um dos especialistas entrevistados, esta má compreensão é mútua, pois assim como os demais setores não entendem o marketing como uma disciplina mais ampla, o marketing também não procura entender os demais setores. Outros fatores causadores desta má compreensão são a ausência de um projeto empresarial global por parte dos profissionais de marketing, conforme citado por um dos entrevistados, e também o fato de por muito tempo o termo "marketing", assim como outros termos em língua estrangeira, não poder ter sido usado nas universidades, conforme instrução do Ministério de Educação e Cultura (MEC), fato este, levantado por um professor entrevistado.

Confundem porque os profissionais que atuam nessa área nunca apresentaram um projeto global na sua empresa, de conhecimento de todos, que diz as diretrizes de um planejamento estratégico da área para determinado ano ou campanha. Podem mudar fazendo isso. (Coordenadora de Marketing)

Um fator que contribuiu para esta percepção é o fato de o MEC não permitir o uso de termos em inglês nas aulas durante muito tempo. Então o marketing foi traduzido como Mercadologia, ou Administração Mercadológica, o que é muito confuso de entender. Nesse meio tempo, surgiram diversas agências de comunicação que se intitulavam de "agências de marketing", sendo que só trabalhavam com comunicação. Essa disseminação das agências contribuiu bastante para que a visão de marketing ficasse limitada ao composto promocional. (Professor) 
O conceito de entender o mercado para atendê-lo, na prática não é visto como uma função do marketing. Os departamentos de marketing nas empresas são restritos, na maioria dos casos, à comunicação. Alguns entrevistados da etapa qualitativa indicaram que seria mais coerente às funções atualmente exercidas pela área nas organizações trocar a nomenclatura atual do setor para departamento de comunicação.

A respeito do conceito proposto pela AMA, com base nessas entrevistas, ainda há certa distância em relação à realidade do Brasil, pois as empresas daqui ainda mantêm seu foco na geração de negócios, preocupando-se mais com os retornos financeiros de curto e médio prazo, do que com a geração de valor ao longo do tempo. Levando em conta as entrevistas com especialistas da área, a solução para esta mudança de percepção talvez consista em os dois lados buscarem este entendimento mútuo do que cada setor representa na organização, ou seja, aplicar o conceito de entender para atender, além de o departamento de marketing buscar ser mais pragmático nas suas ações, apresentando planos concretos e mensuráveis, que objetivem o retorno financeiro à empresa.

Outra medida a ser tomada é a criação de uma filosofia de marketing nas empresas, ou seja, fazer a disciplina ser encarada no seu sentido mais amplo, não apenas do ponto de vista organizacional (marketing como um departamento isolado), mas estratégico, levando em consideração o processo SMP (segmentação, escolha de mercados-alvo e posicionamento), envolvendo, direta ou indiretamente, toda a organização. De acordo com Kotler (2009), o processo SMP representa o pensamento estratégico da empresa para o marketing, a partir do qual ela desenvolve seu composto de marketing, de ordem tática. Em seguida, utiliza as medidas de controle, que servirão para monitorar e avaliar os resultados. O desafio, portanto, consiste em traçar planos coerentes e que possam ter seus resultados mensurados, e criar esta filosofia de marketing dentro das organizações.

\subsection{Tarefas do Marketing}

Outro ponto bastante dúbio nas atividades empresariais, e que foi tratado nesta pesquisa, refere-se às funções do departamento de marketing dentro da organização. Conforme explica Kotler (2000), a principal função do marketing é gerenciar o nível, a velocidade e a composição da demanda. $\mathrm{Ou}$ seja, analisar o comportamento dos clientes e, a partir daí, traçar estratégias de marketing para estimular ou reduzir o consumo.

$\mathrm{Na}$ pesquisa quantitativa, aplicada a profissionais de diversos setores, e com respostas de múltipla escolha, as funções mais citadas estão dispostas na figura a seguir.

Figura 1: Funções do Marketing (respostas múltiplas).

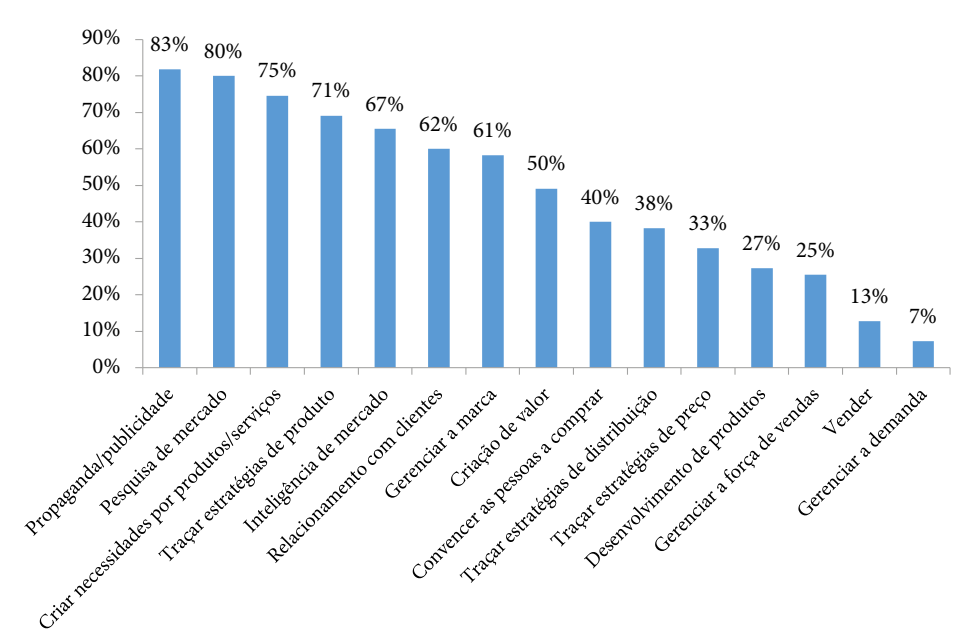

Fonte: Elaboração do próprio autor, com base nos resultados da pesquisa quantitativa aplicada.

É possível relacionar os percentuais da figura 1 com índices iguais ou superiores a $40 \%$ principalmente com alguns elementos do composto de marketing (comunicação e produto), com aspectos mais estratégicos (pesquisa de marketing, inteligência e valor) e com o relacionamento. Mesmo que de forma 
não equilibrada, tais funções estão relacionadas à última definição proposta pela AMA, com exceção do criar necessidade. Aspectos ligados a outros elementos do composto de marketing (distribuição e preço), bem como à demanda e ao processo de venda foram menos indicados.

$\mathrm{O}$ alto índice de respostas que mencionam as estratégias de produto como uma função do marketing provavelmente tenha mais relação à sua venda e comunicação, uma vez que desenvolvimento de produtos obteve menos citações. Na opinião dos entrevistados da etapa qualitativa, o marketing deveria estar mais presente nestas decisões, como um todo, no sentido de trazer informações de mercado que forneçam subsídios para o desenvolvimento de produtos, com o objetivo de suprir as necessidades dos clientes.

Ter interferência no produto. Mas ao mesmo tempo em que deveria fazer, não tem subsídios para fazer, como dinheiro pra fazer pesquisa, por exemplo. Muitas vezes a empresa tem uma filosofia de marketing, que não envolve o departamento em algumas decisões. O marketing cumpre mais o serviço de influenciar os outros setores do que de executar. Quem trabalha com marketing acaba frustrado por não conseguir fazer estas coisas. (Professor)

Não deveria existir um departamento que centralize as funções de marketing. O marketing deveria ser feito por todos, encarado no sentido de satisfazer o cliente. (Professor)

Sobre o que deveria fazer, sou crítico em relação aos "Departamentos de Marketing" das empresas locais, acho que fazem tudo menos marketing, ou parte dele. Acredito que isso é o que menos fazem, e volto a repetir, falta sentir o mercado, estar nele, seja visitando a loja que te revende, seja entendendo mais qual o efeito do seu produto para o cliente. (Publicitário)

Um aspecto muito citado pelos respondentes da etapa quantitativa, que diz que a função do marketing é criar necessidades, traz à tona uma ambigüidade, pois o marketing não cria necessidades. Elas já existem. $\mathrm{O}$ marketing tem a função de estimular o desejo por um produto ou serviço (Campomar \& Ikeda, 2006). Esta função pode ser encaixada na gerência da demanda, que foi a função menos citada pelos entrevistados (apenas 7\% de respostas), por sua relação com incentivo às vendas, uma vez que criar necessidade muitas vezes está atrelado a comprar algo que, em primeira análise, não é necessário. E de fato esta função de gerenciar a demanda é muito pouco compreendida e aplicada na prática. Ela acontece em situações de necessidades de vendas, ou até mesmo não acontece por falta de preparo dos profissionais de marketing.

Acompanhar a demanda é no sentido de quando o desespero aperta, a gente vê o que tem que fazer, e menos no sentido de entender a demanda. (Professor)

Enxergo como algo básico na análise, que por preguiça ou falta de conhecimento, muitos profissionais jogam essa responsabilidade para a agência de PP. (Coordenadora de Marketing).

Considerando, por sua vez, o cruzamento das funções com o tipo de atividade dos profissionais, os ligados à área de marketing indicaram propaganda/publicidade com $89 \%$ (não ligados à área $80 \%$, geral $83 \%$ ), pesquisa de mercado com $83 \%$ (não ligados $77 \%$, geral $80 \%$ ), criar necessidades com $83 \%$ (não ligados $70 \%$, geral $75 \%$ ), estratégias de produto com $78 \%$ (não ligados $67 \%$, geral $71 \%$ ), inteligência de mercado com $83 \%$ (não ligados $57 \%$, geral 67\%), relacionamento com clientes com $61 \%$ (não ligados $63 \%$, geral $62 \%$ ), gerenciar a marca com $78 \%$ (não ligados 53\%, geral 61\%) e criação de valor com $72 \%$ (não ligados 37\%, geral 50\%). Inteligência de mercado, gerenciar a marca e criação de valor, aspectos de cunho mais estratégico, se destacam para quem atua na área. No entanto, chama a atenção o nível de diferença superior associada a criar necessidades, tendo em 
vista as funções desses entrevistados e o que foi comentado anteriormente. Tal evidência merece aprofundamento em estudos futuros.

Infere-se, portanto, que dentro das organizações o profissional de marketing ainda está muito limitado às funções que envolvem o composto promocional. Sua participação em decisões maiores, como estratégias de preço, distribuição e produto, bem como em aspectos de cunho estratégico, no geral ainda é muito pequena, porém é uma situação que deve mudar com o tempo:

O profissional de marketing fica limitado á comunicação, mas seu conhecimento não é jogado fora a partir do momento em que ele consegue influenciar outros setores. Com o tempo a filosofia de marketing nas empresas vai amadurecer. As empresas começam a dar sinais desse amadurecimento. (Professor).

Por outro lado, apesar de diferenças de percepções entre profissionais da área e de outras áreas, há sinais de amadurecimento, com diversas das funções mais citadas de cunho estratégico ou de continuidade do relacionamento, os quais advêm, em boa parte, da grande concorrência entre empresas que oferecem produtos/serviços similares. A partir daí surge a necessidade de diferenciar a oferta. E para criar este diferencial na oferta é que entra a função de inteligência de mercado, também muito citada pelos entrevistados. Em suma, seja por falta de preparo ou de condições de trabalho, os departamentos de marketing têm tido pouca participação em decisões que vão além do composto promocional. Cabe aos profissionais buscarem este espaço por conta própria dentro das organizações, de modo a mudar esta filosofia acerca do marketing, através de informações de mercado, trazidas por pesquisas ou observações próprias. O que não pode, é o profissional de marketing esperar que a empresa lhe dê este espaço de forma natural. É necessário correr atrás desta posição.

\subsection{Importância do Marketing}

Sendo uma área que é encarada entre o limiar de custo e investimento, é interessante analisar a opinião de profissionais acerca da importância que o marketing tem para uma organização. Os resultados da pesquisa quantitativa apontam que $42 \%$ dos entrevistados apontam o Marketing como fundamental, $35 \%$ como muito importante, $11 \%$ como pouco importante, $9 \%$ como importante e $4 \%$ sem importância.

Dentre os entrevistados que julgaram o marketing fundamental ou muito importante, as principais razões apontadas para tal foram: publicidade, posicionamento e diferenciação. A seguir, apresentam-se alguns relatos extraídos do questionário aplicado a profissionais de diversas áreas.

O marketing pode ser o diferencial para a marca, dentro de um mercado cada dia mais competitivo. (Administrador - Pós Graduação)

Não basta ter diferencias no produto e não comunicar isso ao mercado. E não basta também não entender com qual público determinada marca está conversando. Por isso é fundamental para o sucesso de qualquer empresa. (Assistente de Marketing - Graduação Completa)

Propaganda é a alma do negócio. (Auxiliar de Engenharia de Produção - Graduação Incompleta)

Apesar dos resultados positivos da pesquisa, chamou a atenção o número de respondentes que citaram o marketing como um setor pouco importante ou sem nenhuma importância para a empresa, o que demonstra que essa visão de marketing ainda precisa ser melhor esclarecida:

Na empresa que eu trabalho vejo que o marketing não é tão valorizado quanto merece, e acham que o marketing não é força de vendas. (Designer de Interiores - Graduação Incompleta)

Pelo fato da empresa não ter um departamento de marketing, não tenho como mensurar a im- 
portância para a empresa em questão. (Auxiliar de Vendas - Graduação Completa)

Somente quando há lançamento. (Assistente de Engenharia - Graduação Incompleta)

A empresa preocupa-se em preço baixo e nada mais para conquistar clientes e vender. (Designer - Graduação Completa)

Além do cálculo da frequência, verificou-se a média de importância, considerando a seguinte escala: não importante 1 ; pouco importante 2; importante 3; muito importante 4; e fundamental 5. Os resultados apontam para uma média de 4,13 , de 1 a 5 , ou seja, no nível de muito importante. Se for considerada uma equivalência de 100 pontos (ponto $1-0$; ponto $2-25$; ponto $3-50$, ponto $4-75$, ponto 5 - 100), o resultado é de 78,25. Ressalta-se que a variável apresentou comportamento normal, como assimetria de 1,2 e curtose de 0,6 , dentro dos limites estabelecidos por Kline (2005), 3 e 10, respectivamente.

Ademais, foram calculadas as médias para alguns grupos de entrevistados (nível de escolaridade e atuação profissional relacionada ao marketing), e se avaliou se as diferenças eram estatisticamente significantes, através do teste de ANOVA (Malhotra, 2006). Quanto aos entrevistados com nível de escolaridade ensino superior incompleto ou inferior ( $n=16)$, a média foi de 4,19; para o grupo com escolaridade ensino superior completo $(\mathrm{n}=15)$, a média foi de 4,00 ; para o grupo com pós-graduação $(n=17)$, a média foi de 4,18. Com o teste de ANOVA para mais de dois grupos (post-hoc, Tukey), as diferenças de médias não foram estatisticamente significantes ao nível de 0,05 , indicando homogeneidade na opinião.

Quanto às atividades profissionais, os entrevistados que trabalham na área de marketing $(n=18)$ apresentaram média de 4,06, ao passo que os entrevistados não relacionados à área $(\mathrm{n}=30)$ média de 4,17. Apesar da opinião dos que trabalham na área de mar- keting apresentar uma intensidade um pouco inferior à opinião dos que não atuam, tal diferença não é estatisticamente significante ao nível de 0,05. Em relação a isso, e associando a outros resultados, embora o marketing seja encarado como uma área de grande importância, o seu conhecimento ainda é superficial, estando atrelado, na maioria dos casos, ao composto promocional, ou seja, a meios de divulgar a marca e gerar receita através de campanhas publicitárias.

Relacionando estes números com as afirmações dos entrevistados, também é possível afirmar que as empresas têm a visão de que o marketing está relacionado quase que exclusivamente à publicidade/propaganda, e que por conta disso, acreditam que devem despender elevadas somas para manter um departamento de marketing, sendo que são muitos os exemplos de estratégias de baixo custo que geram valor ao cliente e sua retenção ao longo do tempo, como algumas relacionadas à fidelização. Além disso, não é imprescindível que haja um departamento de marketing para que a função seja exercita. Ritchie (2012, p. 33) apresenta a mesma opinião: "Não necessariamente, mas é preciso que haja um compromisso de alto nível e algum tipo de recurso específico que norteie o desenvolvimento da empresa e permita o cumprimento da função estratégica do marketing [...]".

Concluindo, a boa notícia aos profissionais de marketing é de que o departamento é visto como fundamental ou importante para a maioria dos demais setores organizacionais. Porém ainda está muito ligado a altos custos e ao composto promocional. O desafio neste sentido é mostrar às corporações que é possível sim obter lucro através de ações com menor dispêndio financeiro e desenvolver métricas de avaliação eficientes, que comprovem o retorno do investimento. Para tornar isto possível, a tarefa primordial consiste em estabelecer uma filosofia de marketing den- 
tro das empresas, associada à preocupação disseminada em todo a organização em entender e atender os mercados. Neste sentido, as universidades podem contribuir bastante, conforme sugestão de um especialista entrevistado.

O marketing ainda não é visto como uma disciplina ampla porque há poucos autores brasileiros. Tomamos por referências quase sempre autores estrangeiros, que escrevem com base em outra realidade. Neste sentido, as universidades podem contribuir se desenvolverem núcleos de pesquisa de marketing, como ocorre com outros cursos, por exemplo. (Professor)

Ou seja, o primeiro passo é fazer a disciplina ter sua importância reconhecida como filosofia de negócio. Como uma disciplina estratégica que objetive a construção de relações lucrativas de longo prazo. A partir daí, exercer as demais funções ficará mais fácil.

\subsection{Tendências do Marketing}

$\mathrm{O}$ que esperar do marketing daqui pra frente? Quais os principais desafios que os profissionais terão de enfrentar para ter sucesso? Este tópico do artigo reúne a opinião de especialistas e profissionais da área, que foram instigados a dar sua opinião com base em seus conhecimentos acadêmicos e práticos.

O marketing 3.0 é uma filosofia que veio pra ficar. E o que tem de mais forte é que a filosofia das empresas precisa cada vez mais se sensibilizar e entender o ser humano como um ser humano mesmo. Mais do que profissionais fundamentados estrategicamente, as empresas vão exigir profissionais de marketing sensíveis aos conceitos humanos das coisas. Humanização das empresas é um caminho sem volta. (Professor)

A consciência do Marketing 3.0 tem recebido uma relevância maior nos últimos tempos, devido à mudança de comportamento do consumidor, que valoriza muito mais os aspectos humanos nas relações. Os con- sumidores cobram uma transparência muito maior por parte das empresas.

Essa coisa de ter os valores do ser humano no centro das atenções está acontecendo, porque acontece com a sociedade em geral, não é só um privilégio do marketing. $\mathrm{O}$ ganhar a qualquer preço tem sido muito questionado. As pessoas se deram conta de que não dá pra continuar fazendo isso. É errado querer ganhar dinheiro de qualquer jeito e as coisas ganharam um caráter mais humano. (Professor)

Os desafios são busca e implementação de soluções constantes em todas as áreas das empresas (comercial, produção, expedição, PDV), além de aplicá-las e medi-las através de ROI, similaridade de produtos e assertividade no PDV. (Coordenadora de Marketing)

Mas para outro entrevistado, este conceito ainda está longe de chegar ao Brasil.

No Brasil ainda é pouco aplicado. Apenas pelas empresas maiores, que têm acesso a pesquisas e têm recursos para investir. No geral, as empresas ainda enxergam os consumidores como um mecanismo de negócios, de gerar receitas, e não como um ser humano. Uma prova disso são os altos índices de processos (Procon). Se as empresas realmente se preocupassem com o ser humano, não deixariam as coisas chegarem neste ponto. Mas apesar disso, é um caminho a seguir, pois com o tempo os consumidores selecionarão os fornecedores bons, naturalmente. (Professor)

Por fim, o profissional de marketing se vê diante de duas fortes tendências, que já estão se tornando realidade. Além dessa humanização nas relações entre empresas e consumidores, um grande desafio para o profissional de marketing consiste em mensurar o retorno dos investimentos. As crises econômicas ocorridas a partir de 2008 ampliaram a racionalidade dos investimentos em todos os setores. E o marketing, que até então dispunha de poucas ferramentas de análise, teve de se adequar e desenvolver mecanismos de avaliação de desempenho. 


\section{Considerações finais}

Esta pesquisa teve por objetivo analisar o conceito de marketing e sua aplicação na prática, sua importância para as organizações empresariais, estudar como os demais setores enxergam a disciplina e discorrer acerca dos principais desafios aos profissionais de marketing. A partir disso buscou-se a avaliação dos conceitos junto a profissionais e especialistas de Marketing, e a visão de profissionais de diversas áreas sobre a disciplina.

Dentre os principais resultados, pode-se destacar uma falta de consenso geral sobre o conceito de marketing. A pesquisa com profissionais de diversas áreas demonstrou que na visão dos demais setores organizacionais, o marketing está estritamente vinculado principalmente ao composto de comunicação, sendo responsável por promover ações de divulgação da marca ou do produto/serviço oferecido pela empresa. Mesmo entre os especialistas não houve consenso. Enquanto uns conceituam a disciplina no sentido de construir marcas e satisfazer clientes, outra parte busca uma vertente mais pragmática, voltada mais à Administração e busca de retorno financeiro. Todas estas funções compõem o conceito de marketing e fazem parte de suas tarefas na organização, porém o conceito central, proposto por Richers, de entender o mercado para depois atendê-lo, não foi citado diretamente por nenhum dos entrevistados. Em consonância a esta falta de consenso, o conceito proposto pela AMA, que poderia servir para dirimir esta discrepância de percepções, apresenta-se muito vago e pouco aplicado na prática.

Embora para a maioria dos entrevistados, o marketing seja uma área importante, ou muito importante para o desenvolvimento empresarial, no que tange às suas atribuições nas organizações, os resultados apontam que a área ainda está muito limitada ao composto de comunicação, participando muito pouco em decisões estratégicas acerca de produto, preço e formas de distribuição. É notável que o conhecimento da área pode contribuir bastante para o desenvolvimento destes outros elementos do composto de marketing, porém há a necessidade de criar uma filosofia empresarial mais voltada para o marketing, no qual o entender e atender mercados perpasse a toda a organização. Mais do que criar departamentos de marketing, é imprescindível que as empresas adotem uma filosofia de marketing, totalmente voltadas para o mercado e com o objetivo de suprir as necessidades dos clientes. Mas segundo os especialistas entrevistados, há um alento neste sentido, já que as empresas começam a dar sinais de mudança, uma vez que hoje, com a concorrência ferrenha em todos os setores, as mesmas perceberam que têm de criar diferenciais e valores para manter ou conquistar seus clientes. Ainda mais com a forte tendência, do chamado Marketing 3.0, de tratar os consumidores como seres humanos plenos, e não mais como simples ferramentas de negócios.

Como implicações para a prática, o profissional de marketing encontra dois grandes desafios pela frente, para tornar a área vista de forma mais completa. O primeiro deles é criar uma filosofia de marketing nas empresas. Uma filosofia totalmente voltada para o mercado e com foco nos clientes. Um caminho proposto de modo a criar esta filosofia consiste em o profissional de marketing conscientizar a empresa acerca do escopo estratégico da disciplina. Ou seja, demonstrar a importância, os passos e os benefícios que uma estratégia de SMP, principalmente, pode trazer à empresa. Outro caminho que pode contribuir para a criação desta filosofia advém do apoio das universidades, no sentido de criarem ou fortalecerem eventos, oficinas ou núcleos de pesquisa em marketing, o que inclui uma maior aproximação dos profissionais de marketing, bem como no intuito de formar novos profissionais, mais qualificados, para atuar na área. 
O segundo desafio, este mais urgente, consiste em mensurar o retorno dos investimentos em marketing. Por muito tempo as empresas investiram em comunicação, principalmente, sem ter mecanismos científicos de controle de resultados. Dentre os principais indicadores que podem ser usados, é possível destacar os seguintes: market share, ROI, índice de lembrança de marca e evolução de vendas. É importante comparar estes índices antes e depois das campanhas de comunicação. Portanto, criar mecanismos de métricas eficientes é uma tarefa imprescindível para que o Marketing atinja o status estratégico que tanto almeja.

O marketing dentro de grande parte das organizações ainda é visto como uma disciplina que serve de suporte a vendas e que atua somente no composto promocional. Mudar esta percepção é uma tarefa difícil e uma jornada longa, porém totalmente factível. Basta haver uma disposição dos líderes de marketing em trabalhar para gerar consciência do escopo total da disciplina, enfatizando sua contribuição para o sucesso financeiro e de mercado da empresa. No entanto, reforça-se o alerta de Webster Jr. (2009), o qual indica que paradigmas antigos da área, como o composto de marketing e os Quatro Ps são atualmente vistos criticamente, mas que ainda não emergiu um "vencedor" claro na busca por um novo paradigma.

No entanto, Marketing é uma área com amplas possibilidades de crescimento. Segundo Wind (2009), os desafios nos ambientes e na prática do marketing demandam uma perspectiva mais ampla e interdisciplinar, para o desenvolvimento de soluções efetivas. Tendo isso em vista, é necessário primariamente ter disposição para mudar essa consciência de marketing que a maioria das empresas e pessoas têm, e torná-la uma área chave nas organizações, reforçando o conceito de Marketing desenvolvido por Peter Drucker na década de 50 (Darroch, 2009), mas que continua atual: o negócio percebido a partir do ponto de vista do cliente. Nesse sentido, este estudo contribui por deixar claro como o marketing é percebido por profissionais, da área ou não, permitindo avaliar qual a distância em relação ao que é defendido pela academia e associações.

Como limitações, este estudo poderia ter ampliado a pesquisa qualitativa a um grupo de profissionais não atuantes na área. A amostragem, por sua vez, poderia ter considerado outros estratos da população. Como sugestões para futuros estudos, recomenda-se uma pesquisa mais aprofundada a respeito de profissionais da área compreenderem que marketing também é criar necessidades, assim como da relação de marketing com outras áreas organizacionais.

\section{Referências bibliográficas}

Achrol, R. S., \& Kotler, P. (2012). Frontiers of the marketing paradigm in the third millennium. Journal of the Academy of Marketing Science, 40, 35-52.

AMA - American Marketing Association. Disponível em: <http://www.marketingpower.com>. Acesso em: 30 set. 2013.

Baker, M. J. (2005). Administração de marketing. Rio de Janeiro: Elsevier.

Campomar, M. C., \& Ikeda, A. A (2006). Falácias em marketing no Brasil. Anais do Encontro de Marketing da ANPAD, Rio de Janeiro, RJ, Brasil, 2.

Bartels, R. (1988). The History of Marketing Thought. Columbus: Publishing Horizons.

Cobra, M. (1992). Administração de marketing. São Paulo: Atlas.

Darroch. J. (2009). Drucker on marketing: an interview with Peter Drucker. Journal of the Academy of Marketing Science, 37, 8-11. 
Kline, R. B. (2005). Principles and practice of structural equation modeling. New York: Guilford Press.

Kotler, P. (2000). Administração de marketing: a edição do novo milênio. São Paulo: Pearson Prentice Hall.

Kotler, P., \& Keller, K. L. (2006). Administração de marketing. São Paulo: Pearson Prentice Hall.

Kotler, P. (2009). Marketing para o século XXI: como criar, conquistar e dominar mercados. São Paulo: Ediouro.

Kotler, P., Kartajaya, H., \& Setiawan, I. (2010). Marketing 3.0: as forças que estão definindo o novo marketing centrado no ser humano. Rio de Janeiro: Elsevier.

Las Casas, A. L. (2001). Marketing - Conceitos, Exercícios e Casos. São Paulo: Atlas.

Levitt, T. (1985). A imaginação de Marketing. São Paulo: Atlas.

Malhotra, N. (2006). Pesquisa de marketing: uma orientação aplicada. Porto Alegre: Bookman.

Merrian, S. B. (2009). Qualitative research. San Francisco: Jossey-Bass.

Oliveira, S. L. I. (2007). Desmistificando o marketing. São Paulo: Novatec.

Révillion, A. (2001). Inter-relações entre as abordagens de marketing e da teoria da contingência estrutural. REAd - Revista Eletrônica de Administração, 7(3), 1-24.

Richers, R. (2000). Marketing: uma visão brasileira. São Paulo: Elsevier.

Ritchie, C. (2012). Marketing: conceitos essenciais que fazem a diferença. São Paulo: Saraiva.

Rosenwald, P. J. (2005). Accountable marketing: otimizando resultados dos investi- mentos em marketing. São Paulo: Pioneira Thomson Learning.

Rust, R. T., Moorman, C., \& Bhalla, G. (2010). Rethinking marketing. Harvard Business Review, 88(1), 94-101.

Shaw, E. H., \& Jones, D. G. B. (2005). A History of Schools of Marketing Thought. Marketing Theory, 5, 239-281.

Silveira, C. S., Esteves, P. S., \& Rossi, C. A. V. (2013). O que os outros pensam sobre Marketing? A contribuição da disciplina para as ciências sociais. Revista Brasileira de Marketing, 12(2), 49-69.

Troiano, J. (2009). As marcas no divã: uma análise de consumidores e criação de valor. São Paulo: Globo.

Webster Jr, F. (1994). Defining the new marketing concept (Part 1). Marketing Management, 2(4), 22-31.

Webster Jr, F. (2009). Marketing IS management: The wisdom of Peter Drucker. Journal of the Academy of Marketing Science, 37, 20-27.

Wind, J. Y. (2009). Rethinking marketing: Peter Drucker's challenge. Journal of the Academy of Marketing Science, 37, 28-34. 


\title{
Marketing: definitions, applications, trends and professional's challenges
}

\begin{abstract}
This study seeks to analyze how the marketing concept is treated in organizational practices, and the importance of the area for corporations, the main challenges faced by the marketer and trends of the area. Developed this exploratory research, with professional areas related to marketing and also non-related areas, seeking to analyze their perception of the discipline, embedded in the organizational context. There was a limited view of its role, the lack of consensus about its concept and a deep interest in other areas, represented on their opinion of the importance of the area for organizations. Therefore, to stimulate discussion on a possible revision of the role of marketing in business, as well as the functions performed by the professional.
\end{abstract}

Keywords: Marketing Concept. Marketer. Marketing Tasks. Marketing Trends.

\section{Endereço para contato:}

Fabiano Larentis

E-mail: <flarenti@ucs.br>

Endereço: Tray Montenegro, 20/401

CEP 95700-000 Bento Gonçalves, RS 